\title{
YIELD SPREADS AS PREDICTORS OF ECONOMIC ACTIVITY: A REAL-TIME VAR ANALYSIS
}

\author{
N. KUNDAN KISHOR AND EVAN F. KOENIG \\ RESEARCH DEPARTMENT \\ WORKING PAPER 1008
}

Federal Reserve Bank of Dallas 


\title{
Yield Spreads as Predictors of Economic Activity: A Real-Time VAR Analysis
}

\author{
N. Kundan Kishor, University of Wisconsin-Milwaukee \\ Evan F. Koenig, Federal Reserve Bank of Dallas \\ Research Department \\ Federal Reserve Bank of Dallas \\ 2200 N. Pearl Street \\ Dallas, TX 75201 \\ evan.f.koenig@dal.frb.org
}

November 2010

\begin{abstract}
:
We undertake a real-time VAR analysis of the usefulness of the term spread, the junk-bond spread, the ISM's New Orders Index, and broker/dealer equity for predicting growth in non-farm employment. To get around the "apples and oranges" problem described by Koenig, Dolmas and Piger (2003), we augment each VAR we consider with a flexible state-space model of employment revisions. This methodology produces jobs forecasts consistently superior to those obtained using conventional VAR analysis. They are also superior to Federal Reserve Greenbook forecasts and to median forecasts from the Survey of Professional Forecasters. The junk-bond spread is by far the best single predictor of future jobs growth. However, the term spread has some incremental predictive power at medium-to-long horizons. The incremental predictive power of broker/dealer equity, while small, exceeds that of the ISM index at every horizon.

Acknowledgment: We have benefitted from helpful comments by participants in the Empirical Macroeconomics session of the 2010 Western Economic Association Meetings and the joint CIRANO-Federal Reserve Bank of Philadelphia 2010 Conference on Real-Time Data Analysis, Methods, and Applications.

Disclaimer: Views expressed are those of the authors and are not necessarily shared by colleagues at the Federal Reserve Bank of Dallas or the Federal Reserve System.
\end{abstract}




\section{Introduction}

Monetary and fiscal policies affect the economy with a substantial lag. The successful conduct of policy is consequently challenging, as changing circumstances may make actions taken today inappropriate by the time that their influence is fully felt. To minimize this risk, policymakers need accurate forecasts of real activity and inflation that extend out several quarters. Financial-asset prices are attractive for this purpose because they depend heavily on investor expectations that may, depending on the asset, stretch a considerable distance into the future. Moreover, financial asset prices are readily available, updated frequently, and are not typically subject to revision.

The term spread-the difference between yields on long-term and short-term government debt-has attracted considerable attention as an indicator at horizons of interest to policymakers. ${ }^{1}$ It has been the object of numerous academic studies, but is also widely used by business economists and included in the Conference Board's popular Leading Economic Index. In principle, short-term nominal yields can be high relative to long-term yields when investors expect inflation to be lower in the longer-term future than in the near-term future. Typically, though, most of the variation in the nominal term spread is due to variation in the ex ante real term spread, which reflects expected variation in the growth rate of real activity.

Another yield spread that has received some attention as an indicator of future real economic growth is the high-yield or "junk-bond" spread, which is the difference between the yields on below-investment-grade and high-quality corporate (or, sometimes, government) bonds. ${ }^{2}$ Variation in this spread captures changes in perceived default risk on lower-quality bonds, which one would expect to be closely related to future real economic conditions. It also reflects changes in the external finance premium. According to financial accelerator theory, the marginal cost of external funds is a key indicator of credit conditions which, in turn, are an important influence on real activity (Bernanke and Gertler 1995; Bernanke, Gertler and Gilchrist 1999).

Several papers suggest that the term spread lost much of its predictive power for growth in real activity following the Volcker disinflation. ${ }^{3}$ Consistent with this result, the small number of studies that compare the forecast performance of the term spread with that of the junk-bond spread-studies confined largely to the post-Volcker period due to the limited availability of junkbond data-have favored the junk-bond spread. ${ }^{4}$ A concern is that these studies' findings are based 
on short sample periods-sometimes including only a single recession. All of these papers, moreover, ignore the fact that our major indicators of real activity are subject to revision. Failure to take revisions into account can distort tests of marginal predictive power and adversely affect realtime forecast performance.

We bring approximately 10 years of additional data to bear in our re-examination of the predictive power of the term and junk-bond spreads. ${ }^{5}$ We expand the universe of indicators under examination to include the Institute for Supply Management's (ISM) New Orders Index and the market value of securities brokers and dealers. ${ }^{6}$ Recent research by Adrian and Shin $(2008,2009)$ makes the case that broker/dealer equity is a useful measure of intermediation outside of traditional banking channels, and that its growth rate is a powerful predictor of real activity. Finally, ours is a genuinely real-time analysis that confronts the data revision problem. Our findings demonstrate that careful handling of data revisions can result in substantial performance improvements.

The real-time forecasting methodology we employ is that developed by Kishor and Koenig (forthcoming). We use it to predict quarterly growth in non-farm jobs using the indicators discussed above. While there are no revisions to the junk-bond spread, the term spread and broker/dealer equity, and revisions to the ISM index are minor (due solely to re-estimation of seasonal factors), revisions to jobs growth can be substantial even many quarters after initial estimates are released. Typically, forecasters ignore the fact that the data available to them today are subject to revision: They use latest-available data to estimate their equations and then substitute the most recent data releases into these equations to produce forecasts. Because it mixes heavily revised data with first-release and lightly revised data, this “conventional approach” is unlikely to produce good forecasts (Koenig, Dolmas and Piger 2003). Kishor and Koenig propose a variant of VAR analysis that takes data revisions into account without imposing restrictive assumptions on the revisions process. We confirm that this version of VAR analysis produces real-time employmentgrowth and junk-bond-spread forecasts that are superior to those of the conventional approach at every horizon, and produces term-spread forecasts that are superior to those of the conventional approach at most horizons. In a majority of cases, the superiority of our jobs-growth forecasts is statistically significant according to the Giacomini-White test (Giacomini and White 2006). Similarly, a comparison of our real-time jobs-growth forecasts with those of the Survey of Professional Forecasters and the Federal Reserve's Greenbook indicates that our forecasts are 
superior to the alternatives at all but the shortest horizon. Again, these performance differences are statistically significant. Forecasts run from 1995 through the middle of 2008.

Both the junk-bond spread and the term spread contribute importantly to our ability to accurately forecast jobs growth in real time. Without the junk-bond spread, forecast performance deteriorates markedly at all horizons. The term spread is a helpful supplement to the junk-bond spread at longer horizons (three quarters or more). When we try adding the ISM New Orders Index to a forecasting model that includes the junk-bond spread, we find that it has little impact on forecast accuracy. Broker/dealer equity has greater marginal predictive power than the ISM index, but the performance improvement relative to the junk-bond spread alone is, nevertheless, small.

Our results on the usefulness of junk-bond spread confirm, in real time and with an extended sample, the conclusions reported by Gertler and Lown (1999) and Mody and Taylor (2003). Our results on the term spread suggest that it continues to have some usefulness in improving longhorizon forecasts of real growth. Broker/dealer equity may also merit consideration as a secondary indicator. Finally, it is striking that a simple two-variable or three-variable model that makes proper allowance for data revisions so strongly outperforms both a conventionally estimated VAR and private and Federal Reserve Board professional forecasters. This dominance drives home the importance of taking data revisions seriously in economic forecasting exercises. ${ }^{7}$

\section{Methodology}

A relatively simple, 2-variable example will illustrate the data revisions problem and our approach to dealing with it. [Kishor and Koenig (forthcoming) discuss the general case.] The first variable-jobs growth, say-is subject to revision. The second variable-the junk-bond spread (or some other, similar indicator)-is not. An initial official estimate of quarter-t jobs growth and the true value of the quarter- $t$ junk-bond spread are released at the end of quarter $t$. At the end of quarter $t+1$, a revised official estimate of jobs growth becomes available. For the purposes of this discussion only, we assume that the revised estimate is final. In fact, though, it is enough that the revised jobs-growth estimate is efficient. That is to say, it is enough that any subsequent revisions are completely unforecastable using quarter- $(t+1)$ information. ${ }^{8}$ Intuitively, if efficiency holds the law of iterated projections assures us that the best forecast of first-revised jobs growth is also the best forecast of any subsequent estimate. We assume that a VAR describes the evolution of the 
final (or, more generally, the efficient) data. We supplement this VAR with a model of data revisions that is flexible in its assumptions about how the government constructs its early jobsgrowth estimates. We argue that the VAR and the revisions model ought to be estimated together, using seemingly unrelated regression (SUR). The estimated equations are used to project what the most recent jobs-growth data will look like after revision, and it is this projection that is substituted into the VAR to produce forecasts of future jobs growth (and future junk-bond spreads).

Formally, let $x_{1}(t)$ and $x_{2}(t)$ denote the first-revised estimate of quarter- $t$ jobs growth and the actual quarter- $t$ junk-bond spread, respectively. We assume that

$$
\boldsymbol{x}(t)=\mathbf{F} \boldsymbol{x}(t-1)+\boldsymbol{v}(t),
$$

where $\boldsymbol{x}^{\prime}(t) \equiv\left[x_{1}(t) x_{2}(t)\right], \boldsymbol{v}^{\prime}(t)=\left[v_{1}(t) v_{2}(t)\right]$ is vector white noise, and the roots of $\mathbf{F}$ are all of modulus less than one. ${ }^{9}$ In quarter $t$, government statisticians see source jobs data $w_{1}(t)=x_{1}(t)+$ $\eta(t)$, where the measurement error, $\eta$, is white noise with variance $\sigma_{\eta}{ }^{2}$. Based on $w_{1}(t)$ and possibly also $x_{2}(t)$ and a variety of lagged information the government announces a first estimate, $y_{1}(t)$, of quarter-t jobs growth. The data available to private analysts are limited to $y_{1}(t)$ and $x_{2}(t)$ for $t=0$, $2 \ldots, T$; and $x_{1}(t)$ for $t=0,2 \ldots, T-1$. Private analysts don't observe underlying source data unless the government chooses to set $y_{1}(t)=w_{1}(t)$. The analysts' objective is to forecast $\boldsymbol{x}(T+i)(i=1,2, \ldots)$. This requires obtaining estimates $\langle\mathbf{F}\rangle$ and $\langle\boldsymbol{x}(T)\rangle$ of $\mathbf{F}$ and $\boldsymbol{x}(T)$, respectively, and then projecting $\langle\boldsymbol{x}(T)\rangle$ forward according to $\langle\boldsymbol{x}(T+i)\rangle=\langle\mathbf{F}\rangle^{i}\langle\boldsymbol{x}(T)\rangle$. The issue is how best to construct $\langle\mathbf{F}\rangle$ and $\langle\boldsymbol{x}(T)\rangle$.

Most analysts take the government's initial jobs-growth estimates at face value. Specifically, they set $\langle\boldsymbol{x}(T)\rangle^{\prime}=\left[y_{1}(T) x_{2}(T)\right]$ and estimate $\mathbf{F}$ by using OLS to regress $\boldsymbol{x}(t)$ on $\boldsymbol{x}(t-1)$ for $t=1,2 \ldots, T-1$, and $\left[y_{1}(T) x_{2}(T)\right]$ ' on $\boldsymbol{x}(T-1)$. This is what we will call "conventional” VAR estimation and forecasting. Heteroscedasticity makes the conventional estimate of $\mathbf{F}$ inefficient, and it may or may not be biased in finite samples depending on the nature of the revisions process. An additional problem is that $y_{1}(T)$ is not generally the best available estimate of $x_{1}(T)$.

Suppose, for example, that the government publishes $w_{1}(t)$ as its initial estimate of quarter- $t$ jobs growth, so that $y_{1}(t)=w_{1}(t)=x_{1}(t)+\eta(t)=\mathbf{F}_{1} \cdot \boldsymbol{x}(t-1)+v_{1}(t)+\eta(t)$. According to this "noise" 
revisions model, a first-release estimate of quarter- $T$ jobs growth that is high relative to $\mathbf{F}_{1} . \boldsymbol{x}(T-1)$ might be due to a high realization of $v_{1}(T)$ (unexpectedly large actual quarter- $T$ jobs growth), but might also be due to a high realization of $\eta(T)$ (government measurement error). Therefore, the analyst ought not to take $y_{1}(T)$ at face value as an estimate of quarter- $T$ jobs growth. If $v_{1}(T), v_{2}(T)$ and $\eta(T)$ are normally distributed, for example, then $y_{1}(T), x_{1}(T)$, and $x_{2}(T)$ will have a multivariate normal distribution conditional on $\boldsymbol{x}(T-1)$, with

$$
\begin{aligned}
& E\left[x_{1}(T) \mid y_{1}(T), x_{2}(T), \boldsymbol{x}(T-1)\right]= \\
& \mathbf{F}_{1} \cdot \boldsymbol{x}(T-1)+\gamma_{1}\left[y_{1}(T)-\mathbf{F}_{1} \cdot \boldsymbol{x}(T-1)\right]+\gamma_{2}\left[x_{2}(T)-\mathbf{F}_{2} \cdot \boldsymbol{x}(T-1)\right] .
\end{aligned}
$$

Here

$$
\gamma_{1}=\left[\sigma_{1}^{2}\left(1-\rho_{12}^{2}\right)\right] /\left[\sigma_{1}^{2}\left(1-\rho_{12}^{2}\right)+\sigma_{\eta}^{2}\right]
$$

and

$$
\gamma_{2}=\left(\rho_{12} \sigma_{1} / \sigma_{2}\right)\left[\sigma_{\eta}^{2} /\left[\sigma_{1}^{2}\left(1-\rho_{12}^{2}\right)+\sigma_{\eta}^{2}\right]\right]
$$

where $\sigma_{1}{ }^{2}, \sigma_{2}{ }^{2}$ and $\sigma_{\eta}{ }^{2}$ are the variances of $v_{1}(T), v_{2}(T)$ and $\eta(T)$, respectively, and where $\rho_{12}$ is the correlation between $v_{1}(T)$ and $v_{2}(T)$. The two expressions in square brackets on the right-hand side of Equation 2 are the two pieces of new information that the analyst receives at the end of quarter $T$, and $\gamma_{1}$ and $\gamma_{2}$ are the weights that the analyst should place on these pieces of information as he formulates his quarter- $T$ jobs-growth expectations. To the extent that innovations to jobs growth and the junk-bond spread are both driven by changes to the general economic outlook, $\rho_{12}<0$. In these circumstances, according to Equation 2, a rise in the junk-bond spread ought to lead the analyst to expect a downward revision to the government's initial jobs release, insofar as government estimates are not fully reliable in the first place (i.e., insofar as $\sigma_{\eta}{ }^{2}>0$ ). The stronger the correlation between innovations to the junk-bond spread and innovations to jobs growth (the larger in magnitude is $\rho_{12}$ ), the greater the attention that the analyst should pay to the junk-bond spread relative to the government's initial jobs-growth estimates (the larger in magnitude is $\gamma_{2}$ relative to $\gamma_{1}$ ). 
Even if $v_{T}$ and $\eta_{T}$ are not normal, the gain coefficients given above will minimize the expected squared deviation of $\mathbf{F}_{1} \cdot \boldsymbol{x}(T-1)+\gamma_{1}\left[y_{1}(T)-\mathbf{F}_{1} \cdot \boldsymbol{x}(T-1)\right]+\gamma_{2}\left[x_{2}(T)-\mathbf{F}_{2} \cdot \boldsymbol{x}(T-1)\right]$ from $x_{1}(T)$.

By applying ordinary least squares (OLS) to Equation 1, the analyst can obtain consistent estimates of $\mathbf{F}, \sigma_{1}{ }^{2}, \sigma_{2}{ }^{2}$ and $\rho_{12}$. He can use the sample variance of $y_{1}(t)-x_{1}(t)$ to estimate $\sigma_{\eta}{ }^{2}$.

Howrey (1978) generalizes the noise model by allowing the government's estimation errors to be serially correlated:

$$
y_{1}(t)-x_{1}(t)=h\left[y_{1}(t-1)-x_{1}(t-1)\right]+\eta(t),
$$

where $-1<h<1$, and $\eta(t)$ is white noise with variance $\sigma_{\eta}{ }^{2}$. The analyst should set

$$
\begin{aligned}
& \left\langle x_{1}(T)\right\rangle= \\
& \mathbf{F}_{1} \cdot \boldsymbol{x}(T-1)+\gamma_{1}\left\{y_{1}(T)-h\left[y_{1}(T-1)-x_{1}(T-1)\right]-\mathbf{F}_{1} \cdot \boldsymbol{x}(T-1)\right\}+\gamma_{2}\left[x_{2}(T)-\mathbf{F}_{2} \cdot \boldsymbol{x}(T-1)\right],
\end{aligned}
$$

where $\gamma_{1}$ and $\gamma_{2}$ are given by the same formulae as before, in order to minimize expected squared deviations of $\left\langle x_{1}(T)\right\rangle$ from $x_{1}(T)$. Consistent estimates of $\mathbf{F}, \sigma_{1}{ }^{2}, \sigma_{2}{ }^{2}$ and $\rho_{12}$ are obtained by applying OLS to Equation 1 for $t=1,2 \ldots, T-1$. Consistent estimates of $h$ and $\sigma_{\eta}{ }^{2}$ are obtained by applying OLS to Equation 3.

In Sargent (1989), government statisticians observe source data $w_{1}(t)=x_{1}(t)+\eta(t)$, just as in the noise model. However, the government filters $w_{1}(t)$ before releasing an official estimate of $x_{1}(t)$. Specifically, the government sets

$$
y_{1}(t)=\mathbf{F}_{1} \cdot \boldsymbol{x}(t-1)+\gamma_{1}\left[w_{1}(t)-\mathbf{F}_{1} \cdot \boldsymbol{x}(t-1)\right]+\gamma_{2}\left[x_{2}(t)-\mathbf{F}_{2} \cdot \boldsymbol{x}(t-1)\right]+\xi(t),
$$

where the formulae for $\gamma_{1}$ and $\gamma_{2}$ are identical to those in Equation 2, above, and $\xi(t)$ is a whitenoise government filtering error with variance $\sigma_{\xi}{ }^{2}$. The government does the private analyst's work for him, up to white noise.

As far as the private analyst (who lacks access to the government's source data) is 
concerned, the evolution of first-release job growth is described by the equation

$$
y_{1}(t)=\mathbf{F}_{1} \cdot \boldsymbol{x}(t-1)+\gamma_{1}\left[x_{1}(t)-\mathbf{F}_{1} \cdot \boldsymbol{x}(t-1)\right]+\gamma_{2}\left[x_{2}(t)-\mathbf{F}_{2} \cdot \boldsymbol{x}(t-1)\right]+\left[\xi(t)+\gamma_{1} \eta(t)\right]
$$

which is obtained by substituting $w_{1}(t)=x_{1}(t)+\eta(t)$ into Equation 5. It will be convenient to define $\epsilon(\mathrm{t}) \equiv \xi(t)+\gamma_{1} \eta(t)$.

If the government makes no filtering errors $\left(\sigma_{\xi}^{2}=0\right)$, there is no reason to second guess the government's initial jobs release. In general, though, the private analyst will minimize expected squared deviations of $\left\langle x_{1}(T)\right\rangle$ from $x_{1}(T)$ by setting

$$
\left\langle x_{1}(T)\right\rangle=\mathbf{F}_{1} \cdot \boldsymbol{x}(T-1)+\delta_{1}\left[y_{1}(T)-\mathbf{F}_{1} \cdot \boldsymbol{x}(T-1)\right]+\delta_{2}\left[x_{2}(T)-\mathbf{F}_{2} \cdot \boldsymbol{x}(T-1)\right]
$$

where

$$
\delta_{1}=\gamma_{1} \sigma_{1}^{2}\left(1-\rho_{12}^{2}\right) /\left[\gamma_{1}^{2} \sigma_{1}^{2}\left(1-\rho_{12}^{2}\right)+\sigma_{\epsilon}^{2}\right]
$$

and

$$
\delta_{2}=\left(\rho_{12} \sigma_{1} / \sigma_{2}\right)\left(1-\delta_{1}\right) \cdot{ }^{10}
$$

The private analyst can estimate $\mathbf{F}, \gamma_{1}$ and $\gamma_{2}$ by applying non-linear least squares simultaneously to Equations 1 and 6. The regression residuals yield estimates of $\sigma_{1}{ }^{2}, \sigma_{2}{ }^{2}, \rho_{12}$ and $\sigma_{\epsilon}{ }^{2}$. Together, these estimates allow the analyst to calculate $\delta_{1}$ and $\delta_{2}$.

Alternatively, note that Equations 1 and 6 together imply that

$$
y_{1}(t)-x_{1}(t)=\epsilon(t)-\left(1-\gamma_{1}\right) v_{1}(t)+\gamma_{2} v_{2}(t)
$$

It follows that

$$
\operatorname{Cov}\left[y_{1}(t)-x_{1}(t), v_{1}(t)\right]=-\left(1-\gamma_{1}\right) \sigma_{1}^{2}\left(1-\rho_{12}^{2}\right) \leq 0
$$


and

$$
\operatorname{Cov}\left[y_{1}(t)-x_{1}(t), v_{2}(t)\right]=0
$$

Intuitively, the government is able to observe $v_{2}(t)$ before it releases $y_{1}(t)$, and so is able to incorporate in $y_{1}(t)$ the information from $v_{2}(t)$ that is correlated with $x_{1}(t)$. On the other hand, the government can't observe $v_{1}(t)$ until one quarter after the fact and, in consequence, underestimates jobs growth when $v_{1}(t)$ is positive. ${ }^{11}$ A consistent estimate of $\mathbf{F}$ is obtained by applying OLS to Equation $1(t=1,2 \ldots, T-1)$. The residuals from the regression yield consistent estimates of $\sigma_{1}{ }^{2}$, $\sigma_{2}^{2}$, and $\rho_{12}$. Equation 7a can then be used to obtain a consistent estimate of $\gamma_{1}$.

We've seen that Howrey allows for serial correlation in data revisions, but not for correlation between Equation 3's error term and the error term in Equation 1. Sargent's model implies exactly the opposite correlation restrictions. We generalize both models by supplementing Equation 1 with a revisions equation of the form

$$
y_{1}(t)-x_{1}(t)=k\left[y_{1}(t-1)-x_{1}(t-1)\right]+u(t)
$$

where $u(t)$ has mean zero and is serially uncorrelated, but is allowed to be contemporaneously correlated with both $v_{1}(t)$ and $v_{2}(t)$. Howrey's model is the special case where $u(t)$ is uncorrelated with both $v_{1}(t)$ and $v_{2}(t)$. In Sargent's model, $k=0$ and $u(t)$ is correlated only with $v_{1}(t)$.

Our model can easily be put in state-space form, with state equation

$$
\begin{aligned}
& \left\lceil x_{1}(t)\right\rceil\left\lceil f_{11} f_{12} 0\right\rceil\left\lceil x_{1}(t-1)\right\rceil \quad\left\lceil v_{1}(t)\right\rceil \\
& \left|x_{2}(t)\right|=\left|f_{21} f_{22} 0\right|\left|x_{2}(t-1)\right|+\left|v_{2}(t)\right| \text {, } \\
& \left\lfloor x_{3}(t)\right\rfloor \quad\left\lfloor\begin{array}{lll}
0 & 0 & k
\end{array}\left\lfloor x_{3}(t-1)\right\rfloor \quad\lfloor u(t)\rfloor\right.
\end{aligned}
$$

and observation equation

$$
\begin{aligned}
& y_{1}(t)=\left[\begin{array}{lll}
1 & 0 & 1
\end{array}\right]\left\lceil x_{1}(t)\right\rceil, \\
& \left|x_{2}(t)\right| \\
& \left\lfloor x_{3}(t)\right\rfloor
\end{aligned}
$$


where $x_{3}(t) \equiv y_{1}(t)-x_{1}(t)$. Because of correlation between their error terms, Equations 1 and 8 should be estimated using SUR rather than independently (the Howrey approach). The sample period runs from $t=1,2, \ldots T-1$. Once $\mathbf{F}$ and $k$ have been estimated, the Kalman filter is applied to Equations (9) and (10) to obtain an estimate of the current state vector. Equation (9) is then iterated forward to produce forecasts of future jobs growth, future junk-bond spreads, and future jobsgrowth revisions.

In summary, conventional VAR estimation and forecasting suffers from two problems when data are subject to revision. First, VAR coefficients will be inefficiently estimated and possibly biased. Even if the estimated VAR is fine, though, it is typically inappropriate to take end-ofsample data at face value and substitute them into the VAR, unaltered, to produce a forecast. When the latest data are out of line with what one would have predicted given previously available information, the analyst may be able to exploit the discrepancy to successfully predict how government statistical releases will later be revised. By predicting revisions to recent data, the analyst can improve his forecasts of the evolution of the economy.

\section{Data}

We use the junk-bond spread, the term spread, the Institute for Supply Management's New Orders Index, the equity of securities brokers and dealers, and growth in non-farm employment as inputs into our forecasting models. Also, for comparison purposes, we look at median jobs-growth forecasts from the Survey of Professional Forecasters and the Greenbook jobs-growth forecasts prepared by the Board of Governors’ staff before Federal Open Market Committee (FOMC) meetings. We discuss each of these variables, in turn.

The Junk-Bond Spread. As our measure of the high-yield or “junk-bond” spread, we use the difference between the third-month-of-quarter average yields on Merrill Lynch high-yield corporate (cash pay) bonds and Moody’s seasoned AAA corporate bonds. The Merrill Lynch and Moody's series extend back to the first quarter of 1985 and the first quarter of 1962, respectively. (It is the Merrill Lynch series that determines the start date of our VAR analysis.) Neither series is revised. New data are released with a lag of only a couple of days.

Gertler and Lown’s (1999) high-yield data extend back to 1980. Because the character of 
the high-yield market changed in the mid 1980s, however, Gertler and Lown emphasize results from a post-1985 sample.

The junk-bond spread has a strongly negative contemporaneous correlation with currentvintage (August, 2009) quarterly jobs growth over the period from 1985:Q1-2008:Q2 ( $\rho=-0.66$ ). The correlation reaches its maximum magnitude at a 2-quarter horizon $(\rho=-0.73)$. At a 4-quarter horizon, the correlation is -0.61 . See Chart 1 .

The Term Spread. For our term spread we use the difference between the constant-maturity 10-year and 1-year Treasury yields, each measured as a quarterly average. Available data extend back to the second quarter of 1953 for both series. Estimates are available with a lag of only a few days, and are not revised.

Using the 10-year Treasury yield at the long end of the term spread is fairly standard. Feroli (2004), though, uses a 3-year long rate. There is less of a consensus regarding the best rate to use on the short end. Dotsey (1998), Estrella and Mishkin (1998), Feroli (2004) and Rudebusch and Williams (2009) use the 3-month Treasury rate for this purpose. Gertler and Lown (1999), on the other hand, use the 1-year Treasury rate, while the Conference Board uses the federal funds rate to calculate the term spread it includes in its Composite Leading Index.

Over our sample period, the term spread has a negative contemporaneous correlation with quarterly jobs growth $(\rho=-0.26)$. However, it is positively correlated with jobs growth at a 4quarter horizon $(\rho=0.28)$. The correlation reaches its maximum magnitude at an 8-quarter horizon $(\rho=0.48)$. See Chart 2 .

The ISM New Orders Index. The Institute for Supply Management's New Orders Index is a diffusion index that has been released every month, without interruption, since World War II. It is a compilation of assessments from purchasing managers across the country, in a wide variety of manufacturing industries, on whether their firms' orders are expanding or contracting. The index leads quarterly growth in non-farm employment: Since 1985, the contemporaneous correlation between the series is 0.47 ; it rises to 0.52 with the orders index shifted forward one quarter, and falls off to 0.37 with the orders index shifted four quarters (Chart 3). Moreover, the index is comparable to financial data in its timeliness and reliability: The New Orders Index for a given 
month is released on the first business day of the following month and is only revised as a result of an annual re-estimation of seasonal factors, the effects of which are small. In our analysis, we use quarterly averages of monthly data, and we assume that today's data would have been available in real time.

Broker/Dealer Equity. Adrian and Shin (2008) show that growth in the stock market value of securities brokers and dealers has predictive power beyond the term spread for broad measures of economic activity like real household consumption expenditures, real investment, and real GDP. They suggest that this predictive power arises because growth in the market equity of securities brokers and dealers is a good signal of growth in the spare balance sheet capacity of these non-bank financial intermediaries. The Adrian and Shin sample period (1986:Q1 to 2008:Q1) is very similar to ours. However, they ignore the data revisions problem, and do not include the junk-bond spread in their analysis.

We construct our broker/dealer equity variable in much the same way as Adrian and Shin, starting with the 4-quarter growth rate in the market equity of securities brokers and dealers from the Center for Research in Security Prices. Adrian and Shin report only results obtained using this nominal growth measure, but indicate that their findings are robust to deflation of market equity by the chain-weight price index for personal consumption expenditures less food and energy. We deflate, instead, by the consumer price index. The CPI has the advantage, relative to the PCE chain price indexes, that it is not subject to significant revision. (It is revised only as a result of the reestimation of seasonal factors.)

Our broker/dealer equity variable has a 0.00 contemporaneous correlation with quarterly jobs growth. The correlation rises to 0.21 at the 4-quarter horizon, and reaches its maximum (0.24) at the 10-quarter horizon. See Chart 4.

Non-Farm Jobs Growth. Our measure of growth in real economic activity is the annualized quarterly percent change in non-farm employment. The strength of employment growth is of obvious direct concern to policymakers and the public. Moreover, non-farm employment is one of four series included in the Conference Board's Composite Index of Coincident Indicators, and the NBER's Business Cycle Dating Committee refers to it as “probably the single most reliable 
indicator” at business cycle peaks. The series' advantages as a cyclical indicator include its breadth and its timeliness: the initial employment estimate for a given month is typically released on the first Friday of the following month. A disadvantage is that jobs growth estimates are subject to significant revision during the quarter after their initial release. The growth data then remain unchanged (apart from possible minor revision due to re-estimation of seasonal factors) until they undergo a benchmark revision. ${ }^{12}$ First-revision jobs growth estimates (the estimates available with a one quarter lag) appear to be efficient. That is, revisions subsequent to the first revision cannot be predicted given information available at the time of the first revision. Real-time data are available on the Federal Reserve Bank of Philadelphia's website. Chart 5 shows annualized quarterly jobs growth as first released and as it appears today (August 2009).

SPF and Greenbook Jobs-Growth Forecasts. The Survey of Professional Forecasters (SPF), administered by the Federal Reserve Bank of Philadelphia, began soliciting employment forecasts in 2003:Q4. The survey is conducted during the first two weeks of the second month of each quarter, and is released that same month. We extend the SPF jobs-growth forecasts backward in time by using forecasts from the Greenbook briefing document. Specifically, we use Greenbook forecasts prepared by the staff of the Board of Governors in advance of the late-January, late-April, mid-August, and late-October/early-November FOMC meetings. The timing corresponds roughly to that of the SPF survey. At the time of our analysis, 2003 Greenbook forecasts were the most recent available to the public. Using both Greenbook and SPF forecasts, we are able to cover the entire period from 1995:Q1 through 2007:Q2 without any gaps.

The forecasts we consider cover the current quarter and extend out an additional four quarters. Forecasts prepared in 2007:Q2, for example, cover jobs growth in each quarter from 2007:Q2 through 2008:Q2. Forecasts are compared with 2009:Q3-vintage jobs data.

Note that the timing of the SPF surveys and the FOMC meetings gives a clear information advantage to the SPF/Greenbook forecasts relative to our VAR forecasts. Thus, our forecasts are updated four times each year, conditioned on information available during the first weeks of April, July, October and January, respectively, whereas the corresponding Greenbook forecasts are conditioned on information available in late April, early August, late October and late January, and the corresponding SPF forecasts are conditioned on information available in early May, early 
August, early October and early February. The SPF and August Greenbook current-quarter forecasts, in particular, incorporate twice as much direct information about current-quarter jobs growth as would have been available to the analyst using one of our VARs. ${ }^{13}$

\section{Results}

Comparing Indicators. We've argued (see the discussion of methodology, above) for modifying conventional VAR estimation in two respects. First, the data used to estimate the VAR ought not to be a mix of heavily and lightly revised government estimates. Instead, the number of revisions to which the data have been subject ought to be uniform (large enough that subsequent revisions can't be forecasted). Second, the VAR ought to be accompanied by an equation (or, more generally, set of equations) that models the early data-revisions process. This equation should be estimated together with the VAR, using SUR.

We begin by applying our modified methodology to four different two-variable VARs. Each VAR includes first-revision jobs growth together with an indicator variable-either the junk-bond spread, the term spread, the ISM New Orders Index, or growth in broker/dealer equity. Full sample (1985:Q2-2008:Q2) SUR estimates of the VAR-revisions-equation systems show each indicator variable to be useful for predicting jobs growth at the 10-percent significance level or better. (The marginal significance levels attached to the junk-bond spread, the term spread, the ISM index, and broker/dealer equity are 0.000, 0.057, 0.002, and 0.077 respectively.) Each candidate indicator variable, in other words, shows promise. To test real-time predictive performance we estimate each VAR-and-revisions-equation system recursively, over rolling 10-year samples. We used the Kalman filter to project what the initial-release jobs-growth estimate at the end of each sub sample would look like after revision. This projection is substituted into the sub-sample VAR to produce forecasts of jobs growth from 1 to 5 quarters ahead. Table 1 compares these forecasts with actual jobs growth, where "actual" growth is the latest vintage available at the time of our analysis (2009:Q3).

The table shows that the junk-bond spread produces more accurate jobs-growth forecasts than the term spread, the ISM New Orders index, and broker/dealer equity at every horizon. According to the Giacomini-White (2006) forecast comparison test, the performance differences are statistically significant at the 10-percent level or better at nearly all horizons. We conclude that the 
junk-bond spread dominates the other three indicators as a real-time predictor of future jobs growth.

Is there any advantage to adding one of the other indicators to the jobs-growth-junk-bond VAR that does so well in Table 1? Full-sample SUR estimates of three-variable VAR-revisionsequation systems suggest that only the term spread has any marginal predictive power in the presence of the junk-bond spread: The ISM index and broker/dealer equity are statistically insignificant in both the jobs-growth and junk-bond-spread VAR equations, whereas the term spread is significant at just over the 5-percent level $(P=0.052)$ in the junk-bond-spread equation. ${ }^{14}$

Table 2 is the three-variable analog to Table 1 . It compares the real-time predictive performance of a VAR-revisions-equation system in jobs growth, the junk-bond spread and the term spread to the real-time predictive performance of similar systems in jobs growth, the junkbond spread and either the ISM New Orders Index or broker/dealer equity. Although the performance differences are not statistically significant, the broker/dealer system dominates the ISM system at every horizon. Consequently, we drop the ISM index from further consideration. Comparing the broker/dealer and term-spread systems, the former does better at predicting jobs growth at short horizons, while the latter does better at the longest horizons. None of the performance differences is statistically significant.

Comparing the mean-square-jobs-forecast errors reported in Table 1 with those reported in Table 2, it is apparent that adding the term spread to the jobs-growth-junk-bond-spread system substantially improves performance at 4-quarter and 5-quarter horizons, and has little impact on performance at shorter horizons. Adding broker/dealer equity modestly improves performance at all but the longest horizon, where the two-variable and three-variable systems perform about equally well. We conclude that a case can be made for using both the junk-bond spread and the term spread as jobs-growth indicators, but only if one is chiefly interested in forecasting at fairly long horizons. Whether the marginal performance improvement achievable by supplementing the junk-bond spread with broker/dealer equity justifies the additional complexity is a judgement call.

Comparing Methodologies. In Table 3 we compare the performance of our VAR estimation and forecasting methodology to that of conventional practice. By "conventional practice" we mean the practice of using the latest-vintage data available in real time for estimation, and then substituting the most recent data of this vintage into the VAR to produce forecasts-ignoring the possibility that 
these data might later be revised. Rolling 10-year samples are used both in our VAR estimation and in conventional-practice estimation. Table 3 also compares our forecasts with forecasts from the Federal Reserve’s Greenbook and the Survey of Professional Forecasters. (As discussed earlier, the limited availability of the GB and SPF series forces us to splice them together.) All forecasts are compared with jobs-growth data as they appear today (2009:Q3).

The table shows that our methodology nearly always produces lower mean-square forecast errors than conventional practice. With a single exception-broker/dealer equity-this result holds across all the variables included in our analysis and across all forecast horizons. In the 2-variable case, differences in jobs-forecasting performance are statistically significant at the 10-percent level or better at all horizons. In the 3-variable case, jobs-forecasting performance differences are statistically significant at the 1, 2, and 5-quarter horizons when the term spread is the additional indicator. They are statistically significant at all horizons when broker/dealer equity is the additional indicator.

Our methodology also consistently outperforms Greenbook and SPF jobs-growth forecasts-sometimes by a wide margin. The only exception is at the 1-quarter-ahead forecast horizon, where the timing of the Greenbook and SPF forecasts is such that they enjoy a substantial information advantage. (See the discussion of the Greenbook and SPF forecasts in the "Data" section, above.) At medium-to-long horizons (3 and 4 quarters out) and overall (1-to-5 and 2-to-5 quarters out), the performance differences are statistically significant at the 10-percent level or better. It is striking that our simple models fare so consistently well against forecasting professionals.

Recent Performance. Judging by data available in August 2010, non-farm jobs peaked in 2008:Q1 and dropped sharply after the collapse of Lehman Brothers in 2008:Q3. How would an analyst using our approach to try to predict employment have fared in the lead up to this deterioration in the economy? How would he have done relative to the median SPF employment forecast? Chart 6 plots the "actual” path of jobs as it appeared at various dates (the solid lines), along with paths forecasted in selected quarters by SPF participants (dotted lines) or using a Kishor-Koenig-style VAR in jobs, the junk-bond spread, and the term spread (dashed lines). ${ }^{15}$ We assume that the analyst using our approach would have re-estimated the model each quarter. Two cautions are in 
order. First, recall that SPF participants have access to an extra month of data compared to the analyst using our model, giving them an important information advantage whenever economic conditions are rapidly evolving. Second, a sudden near-collapse of the financial system, such as occurred in late 2008, is a very-low-frequency event. Consequently, Chart 6 may not be representative of how our method will perform-either absolutely or relative to the SPF-in the early stages of future recessions.

The chart shows that neither the K-K forecasting model nor SPF participants were particularly successful at giving advance warning of the downturn in employment or predicting its severity. As late as January (K-K) or February (SPF) of 2008, both forecasts called for uninterrupted growth in employment through 2008 and into early 2009. Reflecting, perhaps, their 1-month information advantage, SPF participants were slightly more pessimistic about the strength of this growth. By April (K-K) or May (SPF) of 2008, after a major downward revision to past jobs estimates and a 2008:Q1 jobs decline, both the K-K forecast and the SPF forecast showed jobs dipping slightly and then turning back up. The SPF forecast was more accurate at the 1-quarter and 2-quarter horizons. The K-K forecast did better at more distant horizons. Three months later, the K-K forecast was slightly more pessimistic than the SPF forecast, but both continued to predict a shallow jobs decline of only 3 or 4 quarter's duration. The outlook notably deteriorated after Lehman's collapse. The K-K forecast (updated in early October, using data for September) showed jobs declines continuing unabated over the forecast horizon, while the SPF forecast (updated in early November) showed a more rapid initial drop in jobs followed by a bottoming out and resumption of growth. Forecasts prepared at the beginning of 2009 (early January for K-K and early February for SPF) show a similar pattern: the K-K model predicted continuing job losses, more severe at long horizons than were eventually realized, while the SPF forecast showed a steep initial decline followed by a bottoming out. The K-K forecast is more accurate at horizons 0-3; the SPF forecast is more accurate 4 and 5 quarters out.

Digging Deeper. We've established that our estimation and forecasting procedure can produce large and statistically significant improvements in forecasting performance relative to conventional practice. In this section, we look more closely at the reasons for this improvement in the context of our 2-variable VAR in jobs growth and the junk-bond spread. Except as noted, all results are in- 
sample, using data that run from 1985:Q1-2008:Q2.

We begin by presenting coefficient estimates obtained by applying our approach. The application of SUR to Equations 1 and 8 yields the following results:

$$
\begin{aligned}
& x_{1}(t)=1.515+0.668 x_{1}(t-1)-0.289 x_{2}(t-1) \quad \text { Adj. } \mathrm{R}^{2}=0.737 \\
& (0.305)(0.064) \quad(0.064) \quad \text { S.E. }=0.712 \\
& x_{2}(t)=0.078+0.103 x_{1}(t-1)+0.940 x_{2}(t-1) \quad \text { Adj. } \mathrm{R}^{2}=0.785 \\
& (0.274)(0.057) \quad(0.057) \quad \text { S.E. }=0.641 \\
& y_{1}(t)-x_{1}(t)=-0.054-0.023\left[y_{1}(t-1)-x_{1}(t-1)\right] \quad \text { Adj. } \mathrm{R}^{2}=-0.011 \\
& (0.017)(0.103) \quad \text { S.E. }=0.157
\end{aligned}
$$

where, as in the Methodology section above, $x_{1}(t), x_{2}(t)$, and $y_{1}(t)$ are first-revision jobs growth, the junk-bond spread, and first-release jobs growth, respectively. Note that the estimated value of the $k$ parameter in Equation 8 is statistically insignificant and small in magnitude, indicating that there is no serial correlation in jobs-growth revisions. Bias in initial jobs estimates is small (only 5 basis points), but is highly statistically significant.

The correlations between the error terms in the above equations are quite modest. The estimated matrix of correlation coefficients is given below:

\begin{tabular}{rlcc} 
& \multicolumn{3}{c}{ Correlations Between Model Residuals } \\
\cline { 2 - 4 }$x_{1}(t)$ & $\frac{\underline{x}_{1}(t)}{1.000}$ & $\underline{x}_{2}(t)$ & $\underline{y}_{1}(t)-x_{1}(t)$ \\
$x_{2}(t)$ & & -0.089 & -0.059 \\
$y_{1}(t)-x_{1}(t)$ & & 1.000 & 0.094 \\
& & 1.000
\end{tabular}

The table says that innovations to the junk-bond spread are negatively correlated with innovations to first-revision jobs growth. This finding is consistent with intuition: bad news about prospects for the economy will simultaneously raise the junk-bond spread and lower jobs growth, and vice versa for good news. Government statisticians tend to initially overestimate jobs growth when there has been a positive innovation to the junk-bond spread, indicating that there's room for private analysts 
to use the junk-bond spread to second guess the government. Finally, there is a small tendency for the government to initially underestimate jobs growth in quarters where there has been a positive innovation to jobs growth.

That the residuals from Equation 8 are correlated with innovations to jobs growth and the junk-bond spread is contrary to the assumptions of the Howrey and "noise" revisions models. That the residuals from Equation 8 are correlated with innovations to the junk-bond spread is contrary to the assumptions of the Sargent model. How large are these deviations in practical terms? Applying the formulae that immediately follow Equation 2, the Howrey-model weights on the government's initial jobs report and on innovations in the junk-bond spread are $\gamma_{1}=0.953$ and $\gamma_{2}=-0.005$, respectively. The corresponding Sargent-model weights are $\delta_{1}=0.995$ and $\delta_{2}=-0.0005$, indicating that almost no filtering of the government's initial jobs-growth estimates is required. Our encompassing model of revisions, which imposes no restrictions on the error-term correlation matrix, sets the weights on the government's initial release and junk-bond-spread innovations at 0.943 and -0.021, respectively. Thus, we put less weight the government's initial jobs-growth estimates than do the more-restrictive revisions models, and put more weight on junk-bond-spread innovations.

How much better is our filter than no filter at all (the conventional approach)? Taking official 2009:Q3-vintage jobs-growth estimates as “truth”, the mean-square error of the government's own initial releases is 0.1707 . The mean-square error of our rolling-sample, real-time filtered estimates is 0.1428 . The performance difference is statistically significant at the 10-percent level. (The Giacomini-White $P$ value is 0.058 .)

How important are differences in filtering for forecast performance, as compared with differences in the estimated VAR coefficients? We focus on rolling-sample predictions of jobs growth over the next 5 quarters. According to the top panel of Table 3, proper filtering of initialrelease jobs data combined with proper VAR estimation produces a mean-square-forecast error of 0.6293 when applied to a 2-variable model, as compared with a mean-square error of 0.8199 for the same 2-variable model estimated conventionally, without filtering. The difference in performance is statistically significant at the 10-percent level according to the Giacomini-White test. Suppose, rather artificially, that an analyst uses our preferred VAR-coefficient estimates (our estimates of the F matrix in Equation 1), but then substitutes unfiltered first-release jobs-growth estimates into this 
VAR to produce forecasts. The mean-square-forecast error in this case is 0.6594 , which is only slightly worse than the 0.6293 MSFE achieved by full implementation of our approach. The G-W test applied to the two forecasts has a $P$ value of 0.924 , indicating that neither has a significant performance advantage. If, instead, that the analyst substitutes our filtered current-quarter jobsgrowth estimates into a VAR that has been estimated conventionally, the mean-square-forecast error is 0.7449 -not greatly better than the 0.8199 MSFE achieved by fully conventional estimation and forecasting. (The G-W test of relative forecast performance has a $P$ value of 0.2537 .) Finally, forecasts produced by substituting unfiltered first-release data into a VAR estimated using our method are significantly better than those produced by substituting filtered first-release data into a VAR estimated conventionally. (The G-W test $P$ value for this comparison is 0.0796.) Thus, most of the improvement in forecast performance that we achieve results from our more careful estimation of VAR coefficients rather than from our filtering of initial jobs data. ${ }^{16}$

\section{Conclusions}

We have demonstrated that making proper provision for data revisions can make a big difference in one’s ability to forecast jobs growth in real time. In a VAR setting, "proper provision” means not estimating the VAR equations using latest-available data, which will often consist of a mixture of first-release, lightly revised, and heavily revised government estimates. Instead, the number of revisions to which any variable has been subject ought to be uniform over the sample. “Proper provision” also means supplementing the VAR equations with a model of the early revisions process, so that the most recently released data can be suitably filtered before they are substituted into the VAR to produce a forecast. In the absence of special knowledge, the revisions model should avoid restrictive assumptions. Even very simple models, estimated according to these principles, can outperform sophisticated models estimated conventionally.

Our real-time forecasting analysis finds that the junk-bond spread produces more accurate jobs-growth forecasts than the term spread, the ISM New Orders Index, or broker/dealer equity growth at every horizon. Adding the term spread to a 2-variable VAR in jobs growth and the junkbond spread can be helpful for forecasting at relatively long horizons. The New Orders Index, however, has little or no marginal predictive power. Broker/dealer equity does better than the New Orders Index when introduced into a VAR that includes jobs growth and the junk-bond spread, but 
the improvement remains small. Our results regarding the relative forecasting abilities of the junkbond and term spreads are generally consistent with the existing literature. Our contribution is to show that earlier findings are robust to a lengthened sample period and to an analysis that does not ignore revisions to official estimates of real activity. 


\section{References}

Adrian, Tobias and Hyun Song Shin (2008) "Financial Intermediaries, Financial Stability, and Monetary Policy,” Federal Reserve Bank of New York Staff Report No. 346.

(2009) “Money, liquidity and monetary policy,” American Economic Review 99(2), 600-5.

Bernanke, Ben S. and Mark Gertler (1995) “Inside the black box: The credit channel of monetary policy transmission,” Journal of Economic Perspectives 9, 27-48.

Bernanke, Ben S., Mark Gertler and Simon Gilchrist (1999) “The financial accelerator in a quantitative business cycle framework,” in Handbook of Macroeconomics 1C, edited by John B. Taylor and Michael Woodford (Elsevier Science, North-Holland, Amsterdam), 1341-93.

Chinn, Menzie D. and Kavan J. Kucko (2010) “The Predictive Power of the Yield Curve Across Countries and Time,” NBER Working Paper \#16398.

Dotsey, Michael (1998) “The predictive content of the interest rate term spread for future economic growth,” Federal Reserve Bank of Richmond Economic Quarterly 84(3), 31-51.

Estrella, Arturo, and Gikas A. Hardouvelis (1991) “The term structure as a predictor of real economic activity,” Journal of Finance 46, 555-76.

Estrella, Arturo, and Frederic S. Mishkin (1998) "Predicting U.S. recessions: Financial variables as leading indicators,” Review of Economics and Statistics 80(1), 45-61.

Estrella, Arturo, Anthony P. Rodrigues and Sebastian Schich (2003) "How stable is the predictive power of the yield curve? Evidence from Germany and the United States,” Review of Economics and Statistics 85, 629-644. 
Feroli, Michael (2004) “Monetary policy and the information content of the yield spread,” Board of Governors of the Federal Reserve Finance and Economics Discussion Paper \#2004-44.

Gertler, Mark and Cara Lown (1999) “The information content of the high yield bond spread for the business cycle,” Oxford Review of Economic Policy 15, 132-150.

Giacomini, R. and White, H. (2006) “Tests of conditional predictive ability,” Econometrica 74, 1545-1578.

Howrey, E. Phillip (1978) “The use of preliminary data in econometric forecasting,” Review of Economics and Statistics 60, 193-201.

Kishor, N. Kundan and Evan F. Koenig (forthcoming) "VAR estimation and forecasting when data are subject to revision,” Journal of Business and Economic Statistics.

Koenig, E. F., Dolmas, S., and Piger J. (2003) “The use and abuse of real-time data in economic forecasting," Review of Economics and Statistics 85, 618-628.

Mody, Ashoka and Mark P. Taylor (2003) “The high-yield spread as a predictor of real economic activity: Evidence of a financial accelerator for the United States,” IMF Staff Papers 50(3), 373402.

Rudebusch, Glenn D. and John C. Williams (2009) "Forecasting recessions: The puzzle of the enduring power of the yield curve,” Journal of Business and Economic Statistics 27(4), 492-503.

Stock, James H. and Mark Watson (1989) "New indexes of coincident and leading economic indicators” in NBER Macroeconomics Annual 4, edited by Olivier J. Blanchard and Stanley S. Fischer (MIT Press, Cambridge, Massachusetts), 351-94. 
TABLE 1. Mean-Square Errors, Rolling Jobs-Growth Forecasts from 2-Variable VARs VAR in jobs growth and an indicator variable, estimated as prescribed in main text.

\section{Indicator Variable}

\begin{tabular}{|c|c|c|c|c|}
\hline \hline Horizon & Junk-Bond Spread & Term Spread & ISM New Orders & Broker/Dealer Eq. \\
\hline 1 & $0.5588^{* * *++\neq}$ & 0.8535 & 0.7775 & 0.7180 \\
\hline 2 & $0.6183^{* *+\dagger \neq}$ & 1.2363 & 1.1389 & 1.0547 \\
\hline 3 & $0.8855^{* *+\neq \ddagger}$ & 1.5400 & 1.5525 & 1.3121 \\
\hline 4 & $1.2294^{* \dagger}$ & 1.8594 & 1.9807 & 1.6648 \\
\hline 5 & 1.6433 & 2.0342 & 2.1722 & 1.9740 \\
\hline $1-5$ & $0.6293^{* *+\dagger \neq}$ & 1.1635 & 1.1654 & 0.9963 \\
\hline $2-5$ & $0.8020^{*+\neq}$ & 1.3881 & 1.4281 & 1.2215 \\
\hline
\end{tabular}

* Outperforms term spread at 10\%. $\quad \dagger$ Outperforms ISM at 10\%. $\quad \ddagger$ Outperforms broker/dealer equity at $10 \%$. ** Outperforms term spread at 5\%. $\quad$ †† Outperforms ISM at 5\%. $\quad$ 㧊 Outperforms broker/dealer equity at 5\%.

*** Outperforms term spread at $1 \%$. 
TABLE 2. Mean-Square Errors, Rolling Jobs-Growth and Junk-Bond-Spread Forecasts from a 3-Variable VAR

VAR in jobs growth, junk-bond spread and another indicator, estimated as in main text.

\begin{tabular}{l} 
Indicator: \\
\cline { 2 - 7 } \\
\begin{tabular}{|c|c|c|c|c|c|c|}
\hline Horizon & Jobs Growth & Junk-Bond Sprd. & Jobs Growth & Junk-Bond Sprd. & Jobs Growth & Junk-Bond Sprd. \\
\hline 1 & 0.5797 & 0.4978 & 0.5629 & 0.4853 & 0.5373 & 0.4632 \\
\hline 2 & 0.6449 & 0.9285 & 0.6034 & 0.9275 & 0.5900 & 0.8142 \\
\hline 3 & 0.8708 & 1.4432 & 0.8644 & 1.5084 & 0.8243 & 1.3152 \\
\hline 4 & $1.1467^{\dagger}$ & 1.9906 & 1.2478 & 2.1194 & 1.1563 & 1.8259 \\
\hline 5 & $1.4917^{\dagger+}$ & 2.5186 & 1.6825 & 2.7393 & 1.6600 & 2.4481 \\
\hline $1-5$ & 0.6142 & 1.0980 & 0.6220 & 1.1604 & 0.5874 & 1.0007 \\
\hline $2-5$ & 0.7782 & 1.4234 & 0.8149 & 1.5160 & 0.7576 & 1.3043 \\
\hline
\end{tabular}
\end{tabular}

† Outperforms ISM index at 10\% level. $\quad$ †† Outperforms ISM index at 5\% level. 
TABLE 3. Mean-Square Errors, Rolling Forecasts

Jobs Growth 2-Variable VAR 3-Variable VAR (Term) 3-Variable VAR (Equity)

\begin{tabular}{|c|c|c|c|c|c|c|c|}
\hline Horiz. & GB/SPF & K-K & Conventional & K-K & Conventional & K-K & Conventional \\
\hline 1 & 0.3013 & $0.5588^{\dagger}$ & 0.6307 & $0.5797^{+\dagger}$ & 0.6750 & $0.5373^{\dagger}$ & 0.6086 \\
\hline 2 & 0.9809 & $0.6183^{\dagger}$ & 0.7569 & $0.6449^{\dagger}$ & 0.7601 & $0.5900^{+\dagger}$ & 0.7083 \\
\hline 3 & 1.6228 & $0.8855^{* \dagger}$ & 1.0516 & $0.8708^{*}$ & 0.9597 & $0.8243^{* *+\dagger}$ & 0.9481 \\
\hline 4 & 1.9132 & $1.2294^{* \dagger}$ & 1.5101 & $1.1467^{* *}$ & 1.2916 & $1.1563^{*+}$ & 1.3955 \\
\hline 5 & 2.0965 & $1.6433^{\dagger+}$ & 2.0599 & $1.4917^{\dagger}$ & 1.7104 & $1.6600^{+\dagger}$ & 2.0436 \\
\hline $1-5$ & 1.0820 & $0.6293^{* *+}$ & 0.8199 & $0.6142^{* *}$ & 0.7398 & $0.5874^{* *+\dagger}$ & 0.7545 \\
\hline $2-5$ & 1.4720 & $0.8020^{* *+}$ & 1.0384 & $0.7782^{* *}$ & 0.8919 & $0.7576^{* *+\dagger}$ & 0.9588 \\
\hline
\end{tabular}

\section{Junk-Bond Spread}

\begin{tabular}{|c|c|c|c|c|c|c|c|}
\hline Horiz. & GB/SPF & K-K & Conventional & K-K & Conventional & K-K & Conventional \\
\hline 1 & - & 0.4624 & 0.5029 & 0.4978 & 0.5489 & 0.4632 & 0.5051 \\
\hline 2 & - & 0.8421 & 1.0133 & 0.9285 & 1.1208 & 0.8142 & 1.0137 \\
\hline 3 & - & 1.3307 & 1.4659 & 1.4432 & 1.5916 & 1.3152 & 1.5158 \\
\hline 4 & - & 1.8575 & 2.0091 & 1.9906 & 2.1269 & 1.8259 & 2.0741 \\
\hline 5 & - & 2.4728 & 2.8429 & 2.5186 & 2.7862 & 2.4481 & 2.9010 \\
\hline $1-5$ & - & 1.0121 & 1.1765 & 1.0980 & 1.2621 & 1.0007 & 1.2170 \\
\hline $2-5$ & - & 1.3224 & 1.5240 & 1.4234 & 1.6144 & 1.3043 & 1.5753 \\
\hline
\end{tabular}

\section{Term Spread or Broker/Dealer Equity}

\begin{tabular}{|c|c|c|c|c|c|c|c|}
\hline Horiz. & GB/SPF & K-K & Conventional & K-K & Conventional & K-K & Conventional \\
\hline 1 & - & - & - & 0.0824 & 0.0828 & 711.4 & 682.4 \\
\hline 2 & - & - & - & 0.2106 & 0.2137 & 1496.2 & 1437.0 \\
\hline 3 & - & - & - & 0.4263 & 0.4433 & 2193.1 & 2091.9 \\
\hline 4 & - & - & - & 0.6488 & 0.6989 & 2890.1 & 2774.0 \\
\hline 5 & - & - & - & 0.8073 & 0.8967 & 3332.0 & 3238.8 \\
\hline $1-5$ & - & - & - & 0.3245 & 0.3465 & 1587.6 & 1508.8 \\
\hline $2-5$ & - & - & - & 0.4420 & 0.4741 & 2056.7 & 1966.7 \\
\hline
\end{tabular}

* Outperforms Greenbook/SPF at 10\% level.

** Outperforms Greenbook/SPF at 5\% level. 

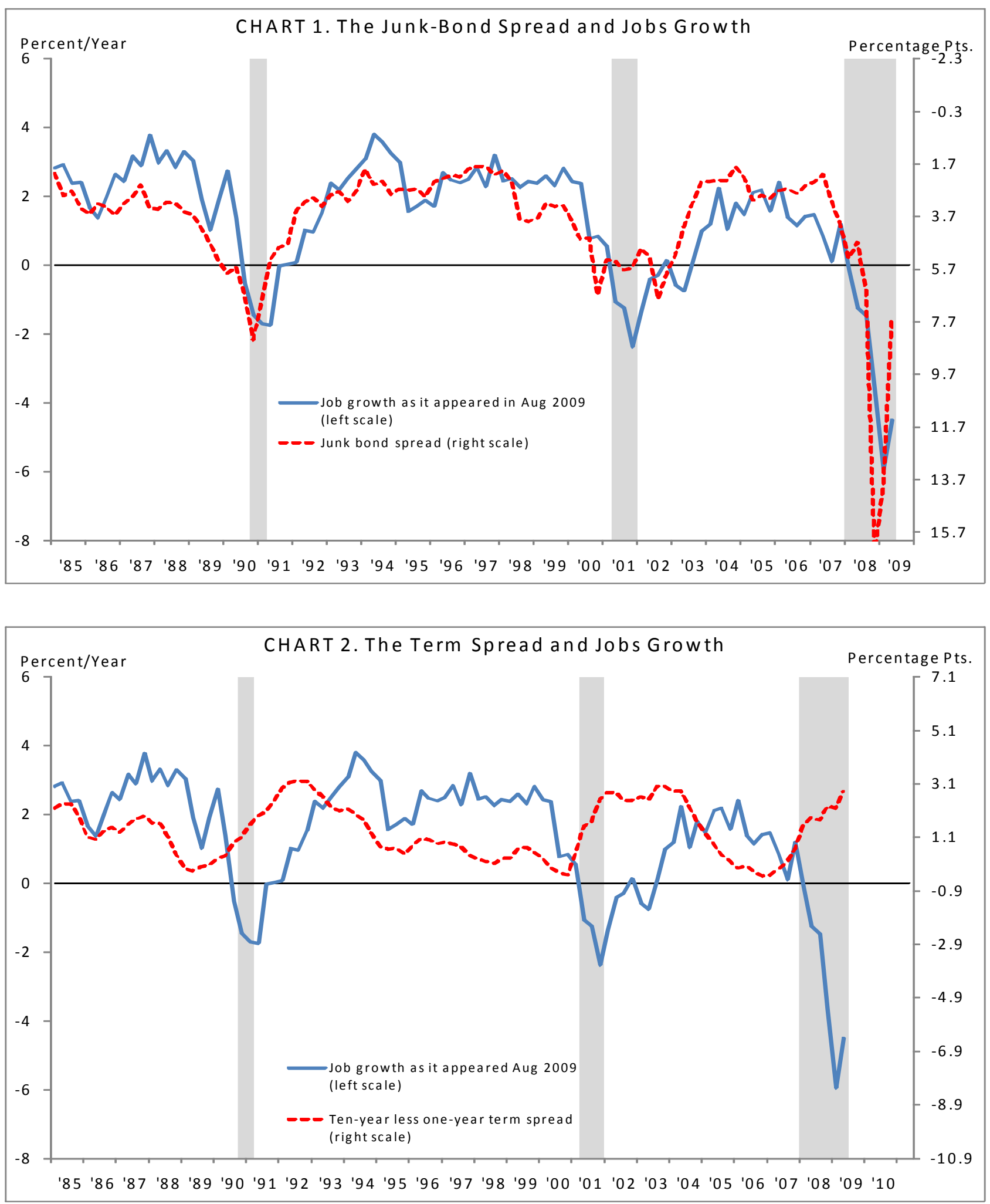

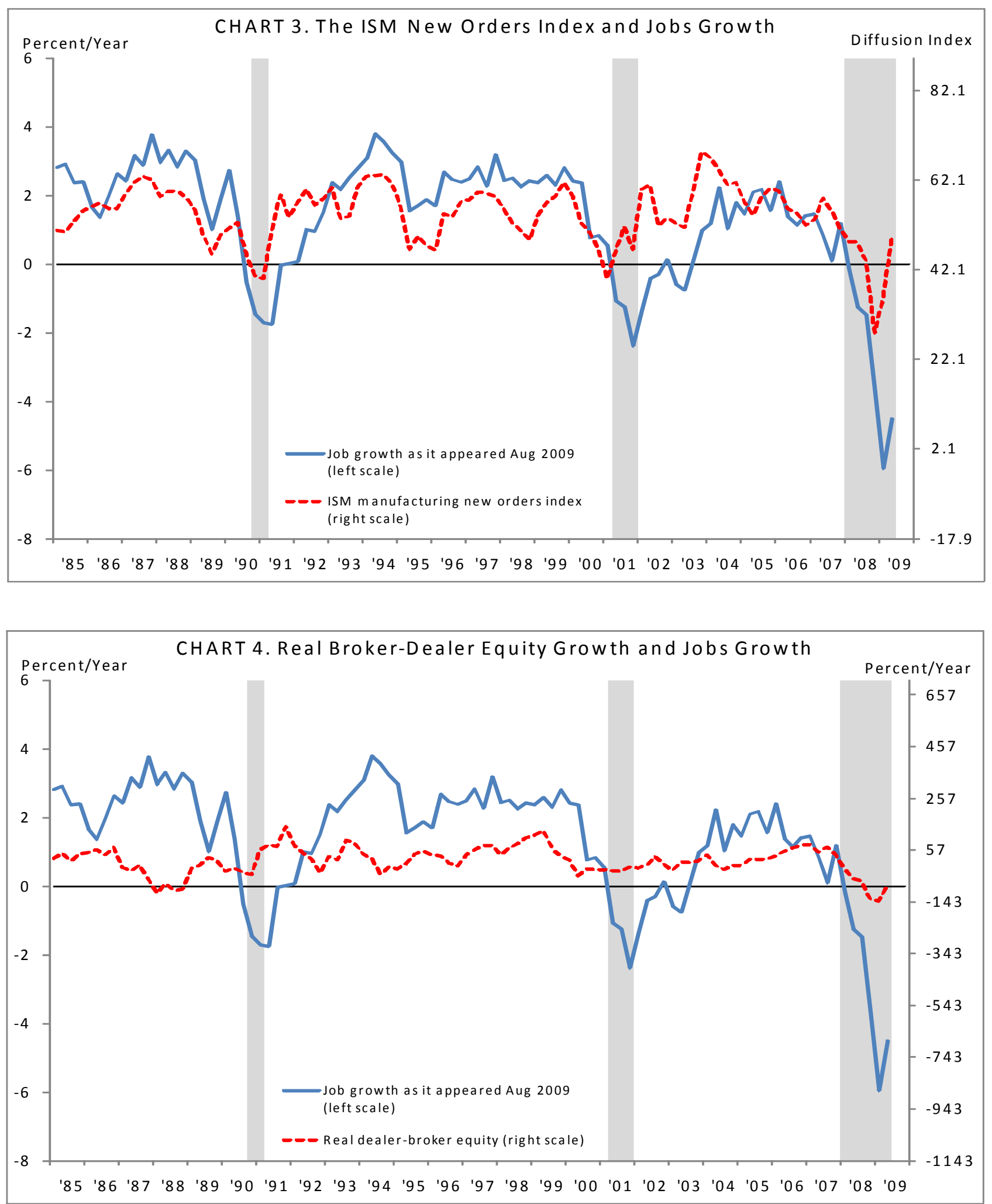


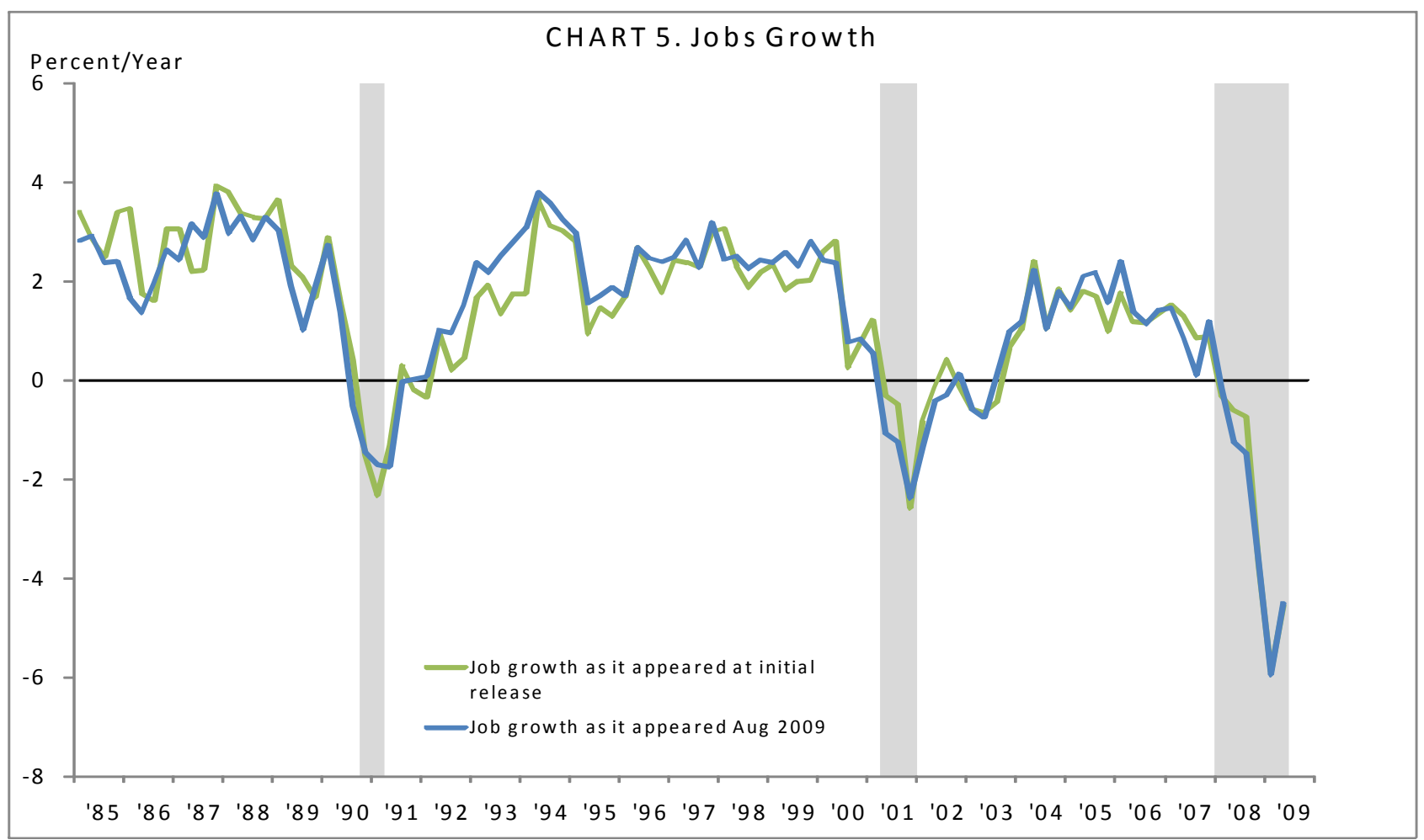




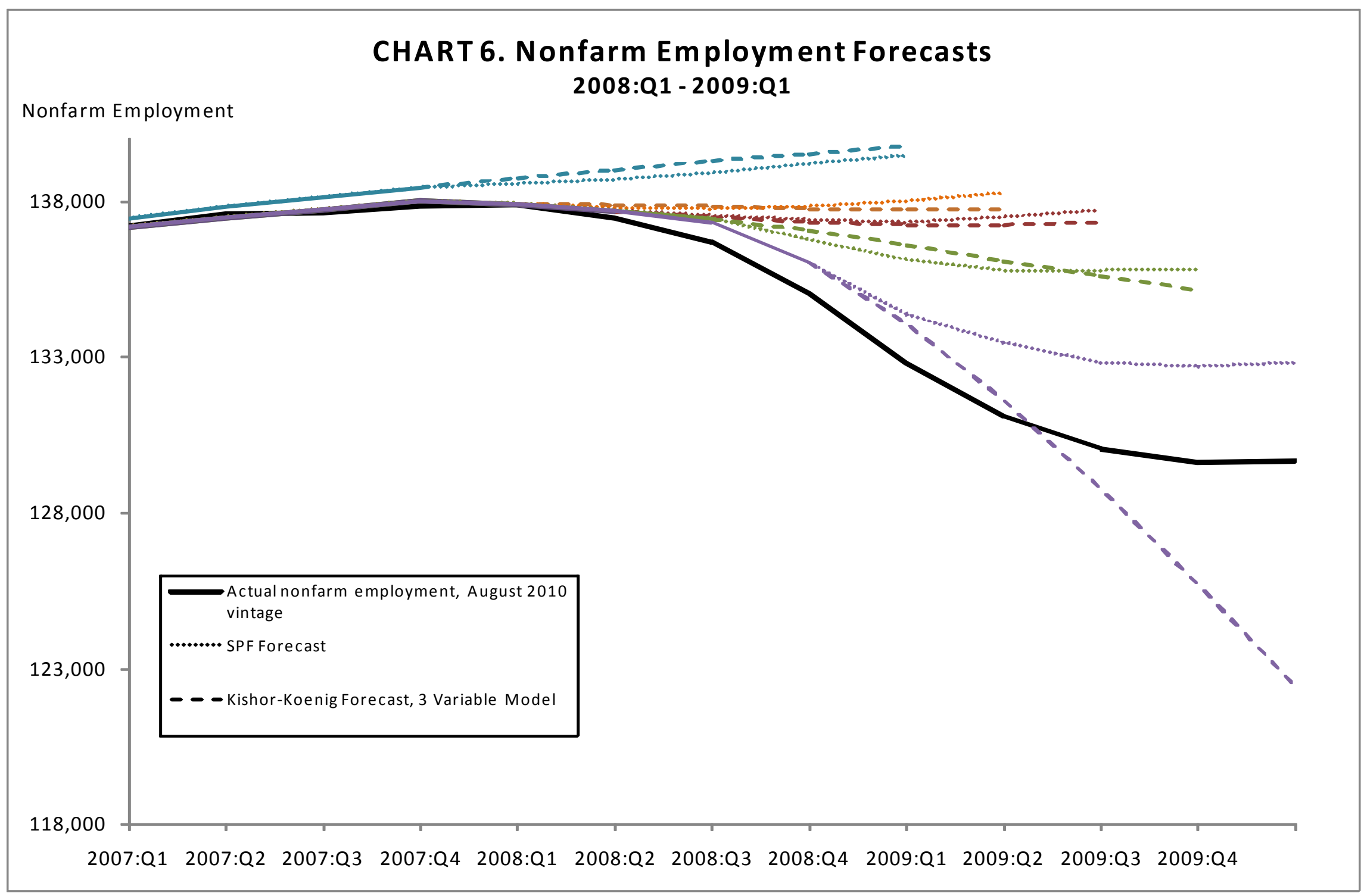




\section{Notes}

1. The literature is vast. Notable contributions include Stock and Watson (1989), Estrella and Hardouvelis (1991), and Estrella and Mishkin (1998).

2. See Gertler and Lown (1999) and Mody and Taylor (2003).

3. See Dotsey (1998), Estrella et al. (2003), Mody and Taylor (2003) and Feroli (2004) for evidence of deterioration in the term spread's predictive power for real growth in the United States. In contrast, the yield curve's ability to forecast recessions appears to have remained intact (Estrella and Mishkin 1998; Rudebusch and Williams 2009). Results for other countries are quite varied (Chinn and Kucko 2010).

4. For comparisons of the indicator properties of the term spread and junk-bond spread, see Gertler and Lown (1999) and Mody and Taylor (2003).

5. Mody and Taylor (2003) base both their claim that the term spread has lost its predictive power for real activity and their claim that the junk-bond spread is a superior indicator on estimates obtained over a 1991:M1-to-2001:M12 sample. Dotsey's (1998) evidence for a deterioration in the term spread's predictive power comes from coefficients estimated over a 1985:Q1-1997:Q4 sample. Similarly, Gertler and Lown (1999) base their conclusions mostly on a 1985:Q1-1999:Q1 sample. In every case, the data cover only one recession. Our data run from 1985:Q1-2008:Q2, and our rolling-sample, real-time forecasts begin in 1995:Q1 and extend, at their furthest, to 2008:Q2.

6. At an early stage we considered a handful of other indicators, including the unemployment rate, real M2 growth, and the federal funds rate. All were dropped from the analysis when it became apparent that they are completely dominated by the junk-bond and term spreads.

7. For an early effort to make this point, see Howrey (1978). Other examples are provided by Koenig, Dolmas and Piger (2003) and Kishor and Koenig (forthcoming).

8. In fact, when we conducted orthogonality tests of the efficiency of first-revision jobs growth estimates, we found we could not reject the hypothesis at standard significance levels.

9. The extension to the case where there are additional lagged values of $\boldsymbol{x}(t)$ on the right-hand side of Equation 1 is straightforward. See Kishor and Koenig (forthcoming).

10. Equivalently, since $\sigma_{\epsilon}^{2}=\sigma_{\xi}^{2}+\gamma_{1}^{2} \sigma_{\eta}^{2}$,

$$
\delta_{1}=\sigma_{1}^{4}\left(1-\rho_{12}{ }^{2}\right)^{2} /\left\{\sigma_{1}^{4}\left(1-\rho_{12}{ }^{2}\right)^{2}+\sigma_{\xi}^{2}\left[\sigma_{1}^{2}\left(1-\rho_{12}^{2}\right)+\sigma_{\eta}^{2}\right]\right\}
$$

and

$$
\delta_{2}=\left(\rho_{12} \sigma_{1} / \sigma_{2}\right)\left\{\sigma_{\xi}{ }^{2}\left[\sigma_{1}{ }^{2}\left(1-\rho_{12}{ }^{2}\right)+\sigma_{\eta}{ }^{2}\right]\right\} /\left\{\sigma_{1}{ }^{4}\left(1-\rho_{12}{ }^{2}\right)^{2}+\sigma_{\xi}{ }^{2}\left[\sigma_{1}{ }^{2}\left(1-\rho_{12}{ }^{2}\right)+\sigma_{\eta}{ }^{2}\right]\right\} .
$$


It is apparent that $0 \leq \delta_{1} \leq 1$.

11. Intuitively, government statisticians quite properly allow for the possibility that the strong source data they see when $v_{1}(t)$ is large are noise rather than news. They discount the incoming information (assigning it a weight of $\gamma_{1}$ ), and release an estimate to the public that is too low.

12. Over most of our sample, the amount of time between initial release and benchmark revision is five quarters for first-quarter jobs growth, six quarters for fourth-quarter growth, seven quarters for third-quarter growth, and eight quarters for second-quarter growth.

13. If $e_{i}(t)$ is the logarithm of employment in month $i$ of quarter $t$, then quarter-t employment growth is equal to $\left[e_{1}(t)+e_{2}(t)+e_{3}(t)\right] / 3-\left[e_{1}(t-1)+e_{2}(t-1)+e_{3}(t-1)\right] / 3=(1 / 3)\left[e_{3}(t)-e_{2}(t)\right]+$ $(2 / 3)\left[e_{2}(t)-e_{1}(t)\right]+\left[e_{1}(t)-e_{3}(t-1)\right]+(2 / 3)\left[e_{3}(t-1)-e_{2}(t-1)\right]+(1 / 3)\left[e_{2}(t-1)-e_{1}(t-1)\right]$. The analyst using our VAR methodology has access only to the final two terms in this expression (with weights $2 / 3$ and $1 / 3$ ), whereas SPF participants have access to the final three terms (with weights $1,2 / 3$ and 1/3). Moreover, the employment data available to SPF participants will have undergone an additional monthly revision.

14. We also looked at impulse response functions from each 3-variable VAR. In the 3-variable system with the term spread, term-spread shocks significantly impact jobs growth five periods later. In the 3-variable systems with the ISM index and with broker/dealer equity, shocks to these variables never significantly impact jobs growth. These impulse response functions were generated with jobs growth and the junk-bond spread placed first and second, respectively, in the ordering of the variables.

15. Consistent with results reported in Table 3, using the 2-variable K-K model (jobs growth and the junk-bond spread) causes some performance deterioration at the longest horizons. The deterioration is negligible, however, except in the 2009:Q1-vintage forecasts.

16. Forecast horizon clearly matters, here. For the current quarter $(h=0)$ the $\mathbf{F}$ matrix is irrelevant and any difference in performance must be due to filtering. As the forecast horizon lengthens, the adjustment path of the economy as reflected in $\mathbf{F}$ comes into play. In the limit, as the forecast horizon goes to infinity, forecasted jobs growth and the forecasted junk-bond spread will converge to their respective long-run means, and differences in forecast performance should disappear. 